\title{
Changes in Local Cerebral Glucose Utilization Induced by the $\beta$-Carbolines FG 7142 and DMCM Reveal Brain Structures Involved in the Control of Anxiety and Seizure Activity
}

\author{
A. Ableitner and A. Herz \\ Department of Neuropharmacology, Max-Planck-Institut für Psychiatrie, D-8033 Planegg-Martinsried, Federal Republic of \\ Germany
}

The brain regions that may be functionally involved in the control of anxiety and the development of seizures were examined using quantitative $1-{ }^{14} \mathrm{C}$-deoxyglucose autoradiography. For this purpose, $\beta$-carbolines FG 7142 and DMCM were employed. They exert their effects via the benzodiazepine receptor, and whereas both possess anxiogenic properties, FG 7142 is a proconvulsant and DMCM a potent convulsant.

The pattern of increases of local cerebral glucose utilization (LCGU) induced by FG 7142 was mainly restricted to limbic structures, such as the lateral septal nucleus, the anterior thalamic nuclei, and the mamillary nuclei. However, structures involved in motor regulation were also affected. A pronounced increase in LCGU was observed in the posterior part of the substantia nigra, pars reticulata. Further, the LCGU of the globus pallidus, the ventral thalamic nucleus, and the cerebellum was increased.

DMCM likewise increased LCGU of the mamillary body and the lateral septal nucleus. In contrast to FG 7142, the hippocampal formation displayed an increase in LCGU, while LCGU of the anterior thalamic nuclei was unchanged. A pronounced increase in LCGU was seen in the substantia nigra, pars reticulata in addition to other structures functionally involved in central motor regulation. The specific benzodiazepine antagonist Ro 15-1788 antagonized the effects of both FG 7142 and DMCM.

It is concluded that the $\beta$-carbolines FG 7142 and DMCM produce selective effects upon LCGU that are mediated by benzodiazepine receptors. The fact that these anxiogenic $\beta$-carbolines, FG 7142 and DMCM, in addition to the anxiolytic diazepam, strongly modify the activity of the mamillary body suggests that this structure may play a key role in the control of anxiety. Since the potent convulsant DMCM, in distinction to the proconvulsant FG 7142, modified LCGU in the hippocampus, this structure may be of major importance for the initiation of seizures by drugs acting via the GABAbenzodiazepine-receptor complex.

\footnotetext{
Received Apr. 21, 1986; revised Aug. 12, 1986; accepted Aug. 18, 1986.

This investigation was supported by the Bundesgesundheitsamt, Berlin. We wish to thank R. Scheiler for the preparation of the manuscript and Dr. M. J. Millan for critical comments.

Correspondence should be addressed to Annemarie Ableitner, Department of Neuropharmacology, Max-Planck-Institut für Psychiatrie, Am Klopferspitz 18a, D-8033 Planegg-Martinsried, F.R.G.

Copyright (C) 1987 Society for Neuroscience $0270-6474 / 87 / 041047-09 \$ 02.00 / 0$
}

The discovery of specific benzodiazepine binding sites in the mammalian central nervous system (Möhler and Okada, 1977; Squires and Braestrup, 1977) prompted the search for endogenous ligands involved in the modulation of anxiety and the regulation of seizures. Several substances such as inosine, hypoxanthine (Asano and Spector, 1979), nicotinamide (Möhler et al., 1979), various peptides (Guidotti ct al., 1978, 1983) and $\beta$-carboline-3-carboxylate-ethylester $(\beta$-CCE) (Braestrup et al., $1980)$ have been proposed to be ligands.

$\beta$-CCE, which was isolated from purified extracts of human urine and rat brain, has been shown to be an extraction artifact (Braestrup et al., 1981). It may, nevertheless, be structurally related to an endogenous ligand, since $\beta$-carboline-carboxylic acid esters and amides are known to bind with high affinity to the benzodiazepine binding site (Braestrup et al., 1980, 1982; Petersen, 1983) but exert actions opposite to those of the benzodiazepines. For example, FG $7142(N$-methyl- $\beta$-carboline-3carboxamide) behaves as a proconvulsant (Little et al., 1984); further, it acts as an anxiogenic in animals (Corda et al., 1983; File and Pellow, 1984) and has been shown to elicit severe anxiety and panic in man (Dorow et al., 1983). Other $\beta$-carbolines such as DMCM (methyl 6,7-dimethoxy-4-ethyl- $\beta$-carboline-3-carboxylate) possess very potent convulsive properties (Braestrup et al., 1982; Petersen, 1983). Moreover, the specific benzodiazepine antagonist Ro 15-1788 blocks both the pharmacological effects of the $\beta$-carbolines and the anxiolytic and the anticonvulsant effects of the benzodiazepines (Braestrup et al., 1982; Nutt et al., 1982).

Hence, it could be proposed that the benzodiazepine receptor plays an important role in the regulation of anxiety and the development of seizures. Therefore, knowledge of the brain regions involved in the actions of benzodiazepines and $\beta$-carbolines, respectively, may prove instructive in the elucidation of the mechanism involved in the development of anxiety and seizures.

Recently, we investigated the effects of diazepam on local cerebral glucose utilization (LCGU) (Ableitner et al., 1985) by use of the $1-{ }^{14} \mathrm{C}$-2-deoxyglucose $\left({ }^{14} \mathrm{C}-\mathrm{DG}\right)$ method (Sokoloff et al., 1977). This method allowed for the simultaneous determination of the changes in activity of various brain regions functionally involved in the pharmacological actions of diazepam. We have extended these studies by an evaluation of the influence upon regional brain glucose utilization of the anxiogenic, proconvulsant $\beta$-carboline FG 7142 and the anxiogenic, potent convulsant DMCM in the rat. 


\section{Materials and Methods}

Preparation of rats. Experiments were performed on male SpragueDawley rats ( $280-310 \mathrm{gm})$. In order to accustom the rats to restraint in the Plexiglas tubes in which they were placed during the experimental procedure, they were restrained in this manner for $1 \mathrm{hr}$ on each of the $3 \mathrm{~d}$ preceding the experiments.

Under light halothane anesthesia, polypropylene catheters were introduced into the left femoral artery and vein. After surgery, the rats were restrained in Plexiglas tubes and allowed to recover from the effects of the anesthesia for at least $2 \mathrm{hr}$.

Drug treatments. FG $7142(5,10 \mathrm{mg} / \mathrm{kg})$ and Ro $15-1788$ were microsuspended in a vehicle (vol/vol, saline $8.6 \%$, propandiol $1.3 \%$, Tween $800.1 \%$ ). DMCM was suspended in $0.5 \%$ methylcellulose (MC) saline solution. DMCM, FG 7142, and the respective vehicles (in control rats) were injected intravenously in a volume of $1 \mathrm{ml} / \mathrm{kg}$, Ro $15-1788$ in a volume of $1.2 \mathrm{ml} / \mathrm{kg}$ body weight. Treatments in the first group of experiments were as follows: control (vehicle) $5 \mathrm{~min}$ before ${ }^{14} \mathrm{C}-\mathrm{DG}$, FG $7142(5$ and $10 \mathrm{mg} / \mathrm{kg}) 5 \mathrm{~min}$ before ${ }^{14} \mathrm{C}-\mathrm{DG}$, Ro $15-1788(5 \mathrm{mg} /$ $\mathrm{kg}) 6 \mathrm{~min}$ before ${ }^{14} \mathrm{C}$-DG + FG $7142(10 \mathrm{mg} / \mathrm{kg}) 5 \mathrm{~min}$ before ${ }^{14} \mathrm{C}-\mathrm{DG}$. Treatments in the second group were as follows: control $(0.5 \% \mathrm{MC}) 1$ min after ${ }^{14} \mathrm{C}-\mathrm{DG}$, DMCM $(1 \mathrm{ml} / \mathrm{kg}) 1 \mathrm{~min}$ after ${ }^{14} \mathrm{C}-\mathrm{DG}$, Ro $15-1788$ $(5 \mathrm{mg} / \mathrm{kg}) 5 \mathrm{~min}$ before ${ }^{14} \mathrm{C}-\mathrm{DG}+\mathrm{DMCM}(1 \mathrm{mg} / \mathrm{kg}) 1 \mathrm{~min}$ after ${ }^{14} \mathrm{C}$ DG. An injection of DMCM following ${ }^{14} \mathrm{C}-\mathrm{DG}$ was selected since we have noted that a short-lasting seizure that occurs prior to ${ }^{14} \mathrm{C}$-DG application does not produce measurable changes in LCGU (A. Ableitner, unpublished observations). Since the results obtained with the ${ }^{14} \mathrm{C}$ DG method predominantly reflect activity in the period of about 5 and $15 \mathrm{~min}$ in which the ${ }^{14} \mathrm{C}$-DG is at a rclatively high concentration in the precursor pool in the tissue, the pattern of regional changes in glucose utilization should be related to sites involved in ictal onset and ictal spread.

Measurement of $L C G U$. LCGU was determined as described by Sokoloff et al. (1977). The experiment was initiated by the injection of 25 $\mu \mathrm{Ci} /$ rat of ${ }^{14} \mathrm{C}-\mathrm{DG}$ via a syringe pump within $30 \mathrm{sec}$. Thirteen arterial blood samples were drawn during the following $45 \mathrm{~min}$. The plasma levels of ${ }^{14} \mathrm{C}$ and glucose were determined by liquid scintillation counting and by a glucose oxidase assay (Beckman glucose analyzer), respectively. The rats were decapitated $45 \mathrm{~min}$ after the onset of the administration of ${ }^{14} \mathrm{C}-\mathrm{DG}$, and the brain was removed and frozen on dry ice. Serial coronal sections $(20 \mu \mathrm{m})$ were prepared in a cryostat maintained at $-20^{\circ} \mathrm{C}$, mounted on coverslips, and dried at $60^{\circ} \mathrm{C}$. The sections were exposed to X-ray film (Mamoray T3, Agfa Gevaert) in light-tight $\mathrm{X}$-ray cassettes for $14 \mathrm{~d}$, together with a series of ${ }^{14} \mathrm{C}$-methylmetacrylate standards precalibrated for $20 \mu \mathrm{m}$ tissue sections (Amersham). To facilitate identification of regions in the autoradiogram, sections adjacent to those used for autoradiography were stained with toluidine blue and examined with reference to the brain atlases of König and Klippel (1963) and Pellegrino et al. (1981). Local tissue concentrations of ${ }^{14} \mathrm{C}$ were evaluated by quantitative densitometric analysis of the autoradiograms (Transmission Densitometer DT 1 105, P.Y., Parry Ltd., U.K.; aperture, $0.2 \mathrm{~mm}$ diameter) with reference to the standards. LCGUs were calculated from brain and plasma radioactivities and plasma glucose concentration using published values for the constants and an operational equation that takes into consideration a variation in the arterial plasma concentration during the experimental period (Savaki et al., 1980).

Statistical analysis. Statistical differences between individual means were assessed by a one way analysis of variance and the Newman Keul's multiple range test.

Materials. $1{ }^{14} \mathrm{C}-2$-D-deoxyglucose (specific activity, $51.3-55.0 \mathrm{mCi} /$ mmol) was obtained from New England Nuclear, Dreieich, FRG; FG 7142 and DMCM were kindly donated by Dr. W. Kehr, Schering, Berlin; and Ro 15-1788 by Dr. W. Haefely, Hottmann-La Roche, Basel, Switzerland.

\section{Results}

Behavior

FG 7142

Following intravenous injection of FG $7142(5$ or $10 \mathrm{mg} / \mathrm{kg}$ ), rats appeared very agitated and attempted to escape from the cylinders; these attempts ceased within a minute. They also commenced to gnaw, a behavior that persisted until completion of the experiment. Myoclonic jerks (1-3 in succession) at in- tervals of 5-10 min were also seen. There was no difference between the doses as regards the development of these symptoms. The jerks elicited by $5 \mathrm{mg} / \mathrm{kg}$, however, appeared somewhat milder. Arterial plasma glucose concentration was found to be increased by both 5 and $10 \mathrm{mg} / \mathrm{kg}$ by about $10 \%$.

Injection of Ro 15-1788 (5 mg/kg, i.v.) prior to FG 7142 (10 $\mathrm{mg} / \mathrm{kg}$ ) prevented the jerks and reduced the excitation, and also inhibited the rise in plasma glucose. Ro 15-1788 alone exerted no effect on behavior or glucose levels as compared with control animals.

\section{$D M C M$}

DMCM (1 mg/kg, i.v.) elicited a 10-20 sec seizure within $2 \mathrm{~min}$ of administration. Seizures were very similar to those elicited by electrical kindling of limbic structures and were classified in accordance with the scheme of Racine (Racine, 1972). Masticatory movements, clonus of the neck, head, and forelimb, and rearing were apparent. These behaviors correspond to stage 4 of Racine's scheme. Following the seizure, myoclonic jerks recurred periodically. The plasma glucose level was raised by about $12 \%$ within 10 min of application. Application of Ro 15$1788(5 \mathrm{mg} / \mathrm{kg}$, i.v. $)$ completely prevented the effects of DMCM.

\section{Effects of FG 7142 on LCGU}

The vehicle itself exerted no effects on LCGU (data not shown). The intravenous administration of FG $7142(5 \mathrm{mg} / \mathrm{kg})$ resulted in a significant increase in glucose utilization in certain regions examined (Table 1). The increases were mainly found in limbic structures: lateral septal nucleus (34\%), anteroventral (24\%) and anteromedial $(25 \%)$ thalamic nucleus, and were most pronounced in the posterior mamillary nucleus (43\%) (Fig. 1). The medial mamillary nucleus displayed a tendency for an increase in LCGU, but this trend did not attain statistical significance. Other areas in which LCGU was increased were the lateral thalamic nucleus ( $17 \%)$, the medial geniculate body ( $18 \%)$, and various regions involved in motor coordination, e.g., cerebellar cortex $(33 \%)$, dentate nucleus (21\%) and substantia nigra, pars reticulata (34\%). In the substantia nigra, however, only the posterior part of the pars reticulata was affected (Fig. 1).

At a higher concentration of FG $7142(10 \mathrm{mg} / \mathrm{kg}$, i.v. $)$, the increases of LCGU in these regions were more pronounced (Table 1). In the posterior mamillary nucleus, LCGU increased by about $70 \%$. Further, LCGU in the globus pallidus, the accumbens nucleus, ventral thalamic nucleus, medial mamillary nucleus, motor nucleus of the trigeminal nerve, cerebellar vermis, and interpositus nucleus was significantly increased at this dose (Table 1).

\section{Effects of DMCM on LCGU}

DMCM $(1 \mathrm{mg} / \mathrm{kg}$, i.v. $)$ increased LCGU in many structures functionally belonging to the limbic system (Table 2). These inlcuded the hippocampus (27\%) and dentate gyrus (36\%) (Fig. 2). A very pronounced increase in LCGU was seen in the lateral septal nucleus $(50 \%)$; further increases were displayed in the accumbens nucleus $(11 \%)$ and the mamillary nuclei $(20 \%)$. However, no changes in LCGU were observed in the anterior thalamic nuclei.

A strong increase was produced in the basal ganglia and functionally related regions (Table 2, Fig. 2) such as the globus pallidus $(41 \%)$, substantia nigra, pars reticulata, in which LCGU increased by more than $90 \%$, and the ventral thalamic nucleus 
A

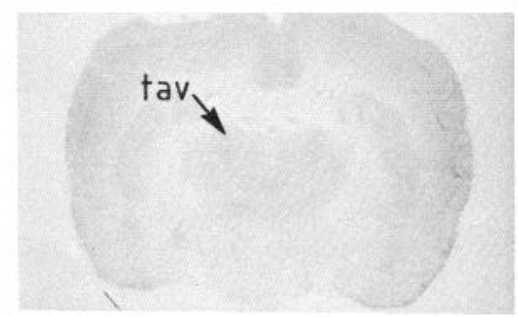

B

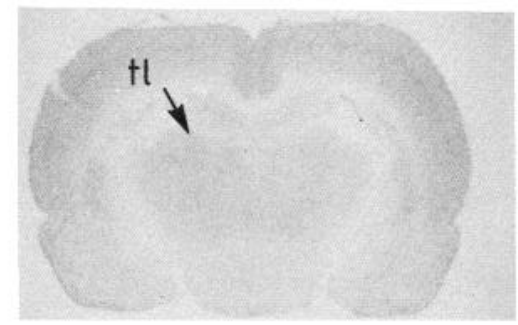

C
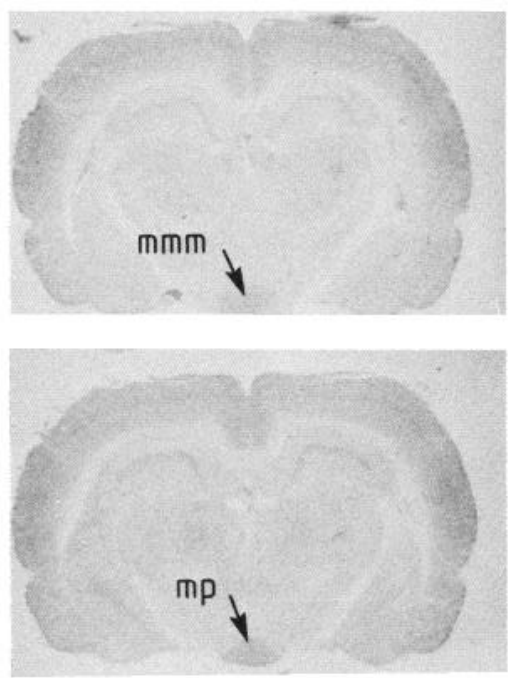

E

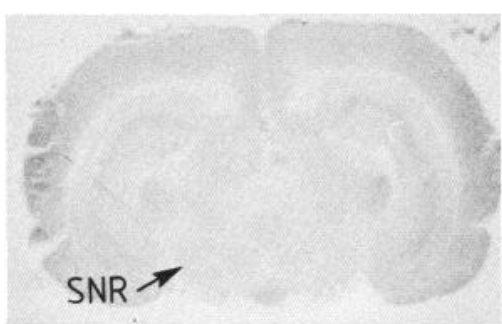

F

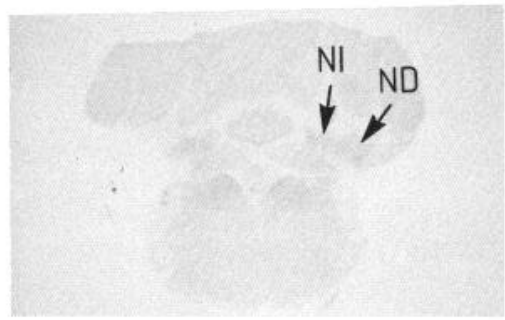

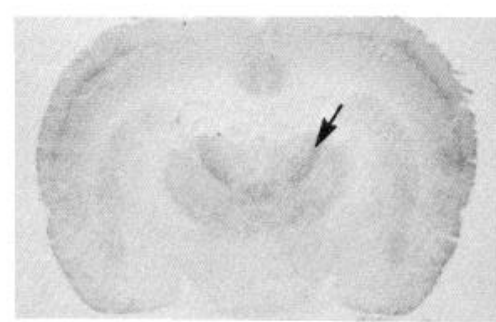
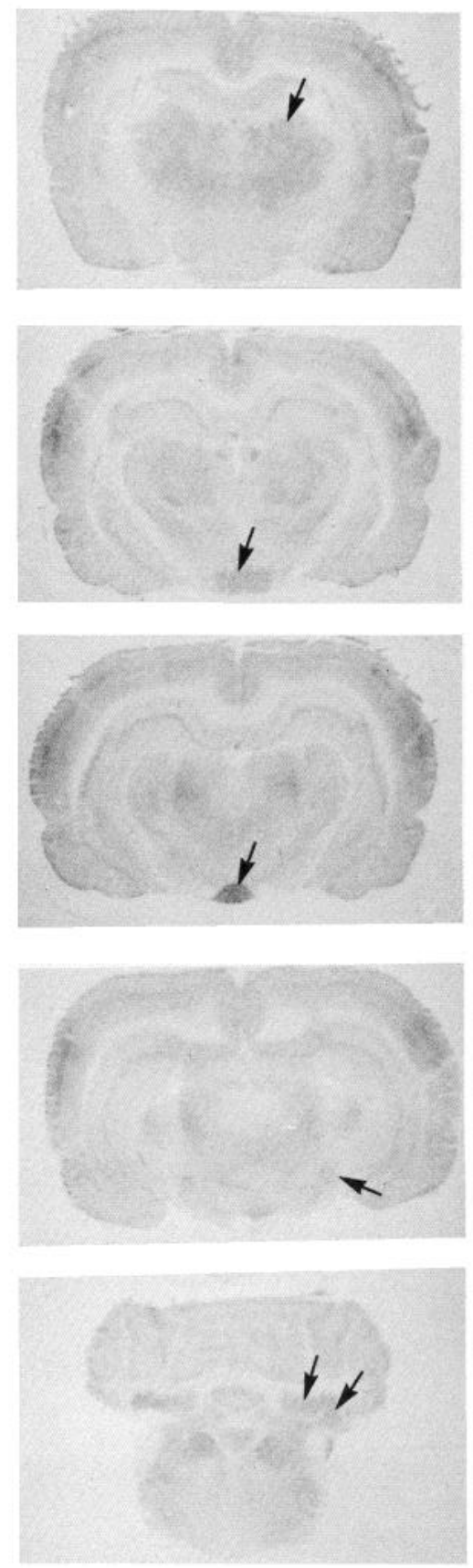

G

$\mathrm{H}$

K

L

Figure 1. Effects of FG 7142 on autoradiographic grain densities, representing glucose utilization. $A-F$, Grain densities in film exposed to sections from different levels of a control brain. $G-M$, Grain densities in film exposed to sections from corresponding brain levels of a rat injected with FG 7142 (5 $\mathrm{mg} / \mathrm{kg}$, i.v.). Abbreviations: tav, anteroventral thalamic nucleus; $t l$, lateral thalamic nucleus; $\mathrm{mmm}$, medial mamillary nucleus, medial part; $m p$, posterior mamillary nucleus; $S N R$, substantia nigra, pars reticulata; $N I$, interpositus nucleus; $N D$, dentate nucleus.
(13\%). In the lateral thalamic nucleus, LCGU increased by $23 \%$. LCGU was significantly increased in cerebellar structures involved in the coordination of movement, e.g., the cerebellar cortex (40\%) and the deep cerebellar nuclei (20\%); furthermore, LCGU was increased in the frontal (14\%) and visual (14\%) cortex (Table 2).
Effects of Ro $15-1788$ on the alterations induced by FG 7142 and DMCM

Ro $15-1788(5 \mathrm{mg} / \mathrm{kg}$, i.v.) produced no alterations of LCGU when applied alone (Table 1). The effects of FG $7142(10 \mathrm{mg} /$ $\mathrm{kg}$, i.v.) were, however, significantly prevented by Ro 15-1788 
Table 1. Effects of FG 7142 upon local cerebral glucose utilization (LCGU) and reversibility of the effects by the specific benzodiazepine antagonist Ro 15-1788

\begin{tabular}{|c|c|c|c|c|c|}
\hline \multirow[b]{3}{*}{ Brain regions } & \multicolumn{5}{|c|}{ LCGU $(\mu \mathrm{mol} / 100 \mathrm{gm} / \mathrm{min})$} \\
\hline & \multirow[b]{2}{*}{ Vehicle } & \multicolumn{2}{|l|}{ FG 7142} & \multirow{2}{*}{$\begin{array}{l}\text { FG } 7142 \\
(10 \mathrm{mg} / \mathrm{kg}) \\
\text { Ro } 15-1788 \\
(5 \mathrm{mg} / \mathrm{kg})\end{array}$} & \multirow{2}{*}{$\begin{array}{l}\text { Ro } 15-1788 \\
(5 \mathrm{mg} / \mathrm{kg})\end{array}$} \\
\hline & & $5 \mathrm{mg} / \mathrm{kg}$ & $10 \mathrm{mg} / \mathrm{kg}$ & & \\
\hline \multicolumn{6}{|l|}{ Telencephalon } \\
\hline Frontal cortex & $100 \pm 3(6)$ & $114 \pm 7(5)$ & $112 \pm 4$ & $111 \pm 4$ & $112 \pm 8$ \\
\hline Visual cortex & $98 \pm 3(6)$ & $98 \pm 6$ & $103 \pm 5$ & $107 \pm 3$ & $103 \pm 1$ \\
\hline Medial amygdaloid nucleus & $46 \pm 1(6)$ & $44 \pm 3$ & $46 \pm 3(6)$ & $41 \pm 1$ & $44 \pm 1$ \\
\hline Lateral septal nucleus & $49 \pm 1(6)$ & $66 \pm 2(4)^{b}$ & $75 \pm 5(6)^{b}$ & $53 \pm 3(4)$ & $49 \pm 2$ \\
\hline Caudate nucleus & $97 \pm 3(6)$ & $100 \pm 6$ & $104 \pm 3$ & $109 \pm 3$ & $97 \pm 2$ \\
\hline Globus pallidus & $55 \pm 1(6)$ & $61 \pm 4$ & $65 \pm 2(6)^{b}$ & $59 \pm 1$ & $58 \pm 1$ \\
\hline Accumbens nucleus & $83 \pm 1(6)$ & $95 \pm 5$ & $100 \pm 5(6)^{a}$ & $95 \pm 5$ & $86 \pm 4$ \\
\hline Ventral thalamic nucleus & $92 \pm 3(6)$ & $106 \pm 8$ & $113 \pm 4(6)^{b}$ & $112 \pm 6$ & $93 \pm 4$ \\
\hline Hypothalamus ventromedial nucleus & $51 \pm 1(6)$ & $51 \pm 3$ & $55 \pm 3(6)$ & $53 \pm 2$ & $50 \pm 1$ \\
\hline Medial mamillary nucleus, medial part & $106 \pm 4(6)$ & $127 \pm 8$ & $144 \pm 8(6)^{c}$ & $120 \pm 5(4)^{d}$ & $106 \pm 4$ \\
\hline Posterior mamillary nucleus & $98 \pm 5(5)$ & $141 \pm 13(5)^{b}$ & $170 \pm 10(6)^{c}$ & $124 \pm 10(4)^{e}$ & $99 \pm 3$ (4) \\
\hline Lateral geniculate body & $74 \pm 2(6)$ & $80 \pm 6$ & $83 \pm 2(6)$ & $84 \pm 5$ & $72 \pm 2$ \\
\hline Medial geniculate body & $106 \pm 4(6)$ & $126 \pm 9(5)^{a}$ & $137 \pm 4(6)^{h}$ & $132 \pm 5$ & $116 \pm 7$ \\
\hline \multicolumn{6}{|l|}{ Mesencephalon } \\
\hline Substantia nigra, pars reticulata & $53 \pm 2(6)$ & $59 \pm 5$ & $63 \pm 6(6)$ & $55 \pm 4$ & $62 \pm 2$ \\
\hline Substantia nigra, posterior part & $61 \pm 1(6)$ & $82 \pm 5(5)^{a}$ & $96 \pm 6(6)^{b}$ & $84 \pm 6$ & $69 \pm 2$ \\
\hline Superior colliculus & $88 \pm 6(6)$ & $74 \pm 6$ & $79 \pm 6 \quad(6)$ & $98 \pm 2$ & $102 \pm 2$ \\
\hline Interpeduncular nucleus & $97 \pm 4(6)$ & $98 \pm 8$ & $102 \pm 7(6)$ & $116 \pm 4$ & $101 \pm 2$ \\
\hline Dentate nucleus & $91 \pm 2(6)$ & $109 \pm 9(5)^{a}$ & $118 \pm 4(6)^{c}$ & $107 \pm 4$ & $103 \pm 4$ \\
\hline Interpositus nucleus & $98 \pm 3(6)$ & $112 \pm 9$ & $120 \pm 5(6)^{a}$ & $111 \pm 3$ & $103 \pm 3$ \\
\hline \multicolumn{6}{|l|}{ White matter } \\
\hline Genu of corpus callosum & $25 \pm 1(6)$ & $24 \pm 1$ & $26 \pm 2$ & $30 \pm 1$ & $26 \pm 1$ \\
\hline Internal capsule & $29 \pm 1(6)$ & $31 \pm 1$ & $32 \pm 3$ & $34 \pm 1$ & $31 \pm 1$ (4) \\
\hline Cerebellar white & $29 \pm 1(6)$ & $29 \pm 1$ & $33 \pm 2(6)$ & $36 \pm 1$ & $32 \pm 1$ \\
\hline
\end{tabular}

Values shown are means \pm SEM for the number of rats indicated in parentheses.

${ }^{a} p<0.05,{ }^{b} p<0.01,{ }^{c} p<0.001$ significantly different from vehicle.

${ }^{d} p<0.05,{ }^{e} p<0.01,{ }^{f} p<0.001$ significantly different from FG $7142(10 \mathrm{mg} / \mathrm{kg})+\mathrm{Ro} 15-1788(5 \mathrm{mg} / \mathrm{kg})$.

in structures belonging to the limbic system: the lateral septal nucleus and the mamillary nuclei. In the other regions, slight (nonsignificant) attenuations were seen (Table 1, Fig. 3). Ro 151788 completely prevented the effect of DMCM in all regions (Table 2).

\section{Discussion}

The 2-DG method (Sokoloff et al., 1977) was used to elucidate the brain regions involved in the modulation of anxiety and seizure activity by $\beta$-carbolines. The pattern of regional changes in glucose utilization obtained by this method following admin- istration of a drug is a reflection of the coupling of the drug with a receptor population situated on particular neurons (primary effects) and secondary effects mediated via an interaction of these neurons with other neurons, the latter possibly located in other brain regions.

There was a limited correlation between the anatomical distribution of benzodiazepine receptors (Young and Kuhar, 1980) and the regions in which changes in LCGU following application of $\beta$-carbolines were seen. Such a lack of conformity has generally been the case with other drug classes (Dow-Edwards et al., 1981; Palacios et al., 1982) and is to be explained by the 
A
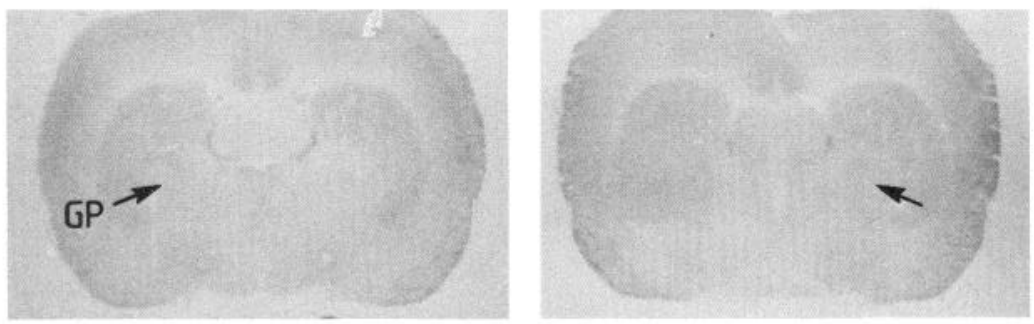

B
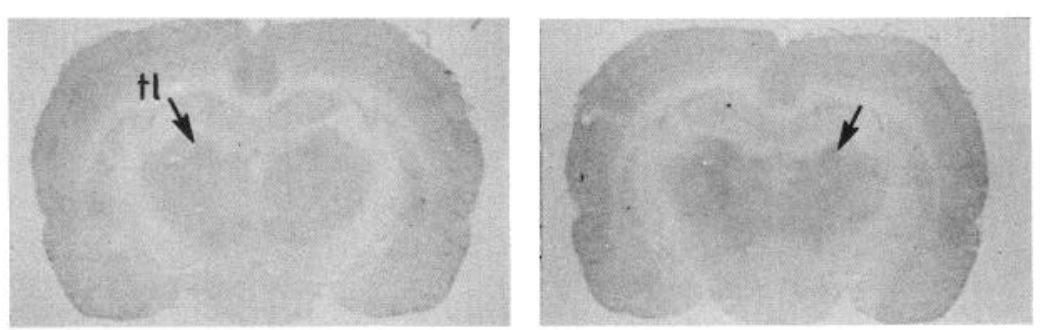

C

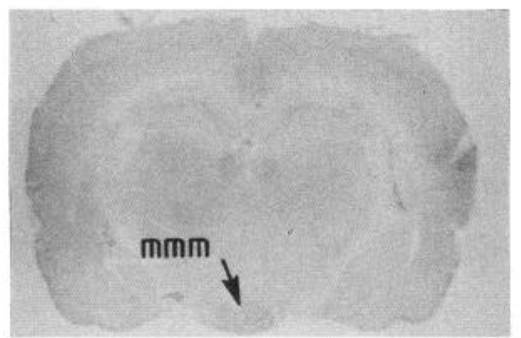

D

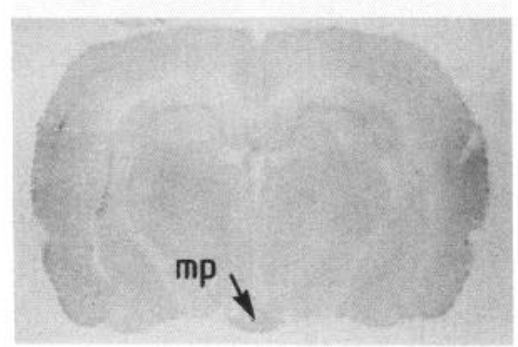

E

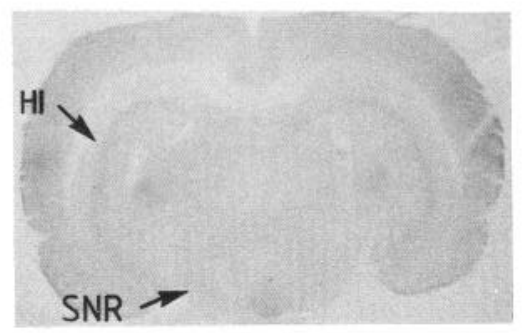

$\mathrm{F}$

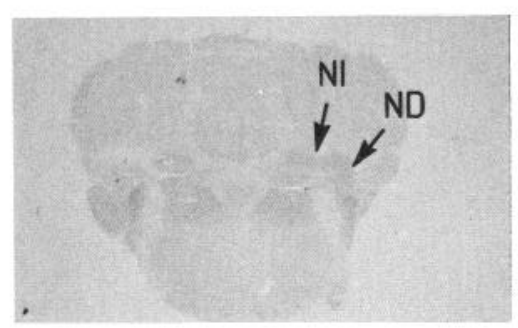

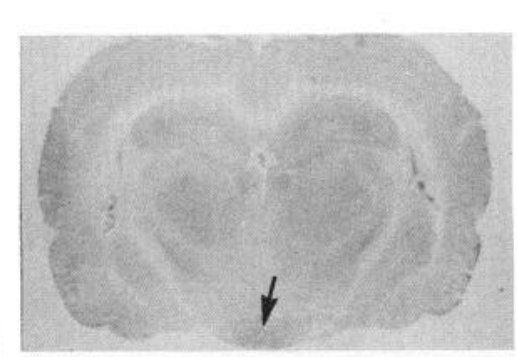
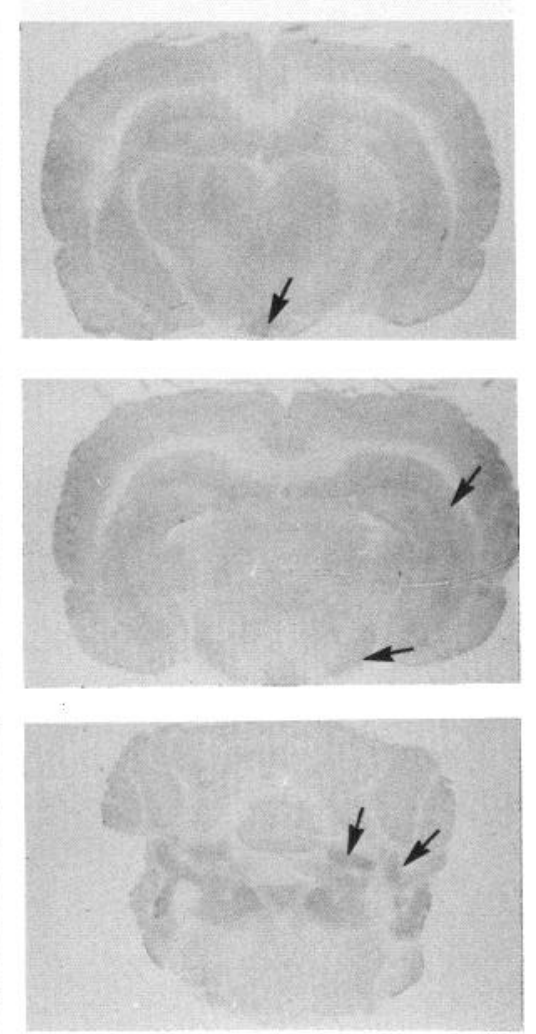

G

$\mathrm{H}$

I

$\mathrm{K}$

$\mathrm{L}$

Figure 2. Effects of DMCM on autoradiographic grain densities, representing glucose utilization. $A-F$, Grain densities in film exposed to sections from different levels of a control brain. $G-$ $M$, Grain densities in film exposed to sections from corresponding brain levels of a rat injected with DMCM $(1 \mathrm{mg} / \mathrm{kg}$, i.v.). Abbreviations: $G P$, globus pallidus; $t l$, lateral thalamic nucleus; $\mathrm{mmm}$, medial mamillary nucleus, medial part; $m p$, posterior mamillary nucleus; $H I$, hippocampus; $S N R$, substantia nigra, pars reticulata; $N I$, interpositus nucleus; $N D$, dentate nucleus. complexity of neuronal circuitries presumed to underlie druginduced changes in LCGU.

A comparison of the pattern of changes in LCGU induced by FG 7142 with those of the anxiolytic and anticonvulsant diazepam (Ableitner et al., 1985) revealed a broad conformity, but whereas diazepam decreased, FG 7142 increased, LCGU.
This regional parallelism despite their constrasting actions reflects the fact both FG 7142 and diazepam operate via the benzodiazepine receptor-and therefore affect the same pathways and neuronal circuitries-but that they modify their function differently (Braestrup et al., 1983b). Whereas diazepam facilitates, FG 7142 decreases GABAergic transmission. In the 
Table 2. Effects of DMCM upon local cerebral glucose utilization (LCGU) and antagonism of these effects by the specific benzodiazepine antagonist Ro 15-1788

\begin{tabular}{|c|c|c|c|}
\hline \multirow[b]{2}{*}{ Brain regions } & \multicolumn{3}{|c|}{$\underline{\operatorname{LCGU}}(\mu \mathrm{mol} / 100 \mathrm{gm} / \mathrm{min})$} \\
\hline & Vehicle & $\begin{array}{l}\mathrm{DMCM} \\
(1 \mathrm{mg} / \mathrm{kg}) \\
\end{array}$ & $\begin{array}{l}\text { DMCM } \\
(1 \mathrm{mg} / \mathrm{kg})+ \\
\text { Ro } 15-1788 \\
(5 \mathrm{mg} / \mathrm{kg}) \\
\end{array}$ \\
\hline \multicolumn{4}{|l|}{ Telencephalon } \\
\hline Frontal cortex & $109 \pm 4(4)$ & $124 \pm 2(5)^{c}$ & $99 \pm 3(4 y$ \\
\hline Visual cortex & $99 \pm 2(4)$ & $113 \pm 3(5)^{a}$ & $104 \pm 3(4)^{d}$ \\
\hline Hippocampus & $89 \pm 4(4)$ & $113 \pm 10(5)^{a}$ & $88 \pm 2(4)$ \\
\hline Dentate gyrus & $58 \pm 3(4)$ & $78 \pm 9(5)^{a}$ & $53 \pm 2(4)^{d}$ \\
\hline Medial amygdaloid nucleus & $46 \pm 2(4)$ & $47 \pm 2$ & $43 \pm 5(4)$ \\
\hline Lateral septal nucleus & $50 \pm 2(4)$ & $76 \pm 5(5)^{c}$ & $42 \pm 4(4)^{\gamma}$ \\
\hline Caudate nucleus & $104 \pm 4(4)$ & $107 \pm 2$ & $94 \pm 3(4)$ \\
\hline Globus pallidus & $60 \pm 2(4)$ & $85 \pm 3(5)^{c}$ & $53 \pm 2(4 y$ \\
\hline Accumbens nucleus & $95 \pm 3(4)$ & $106 \pm 3(5)^{b}$ & $86 \pm 2(4)$ \\
\hline \multicolumn{4}{|l|}{ Diencephalon } \\
\hline Anteroventral thalamic nucleus & $104 \pm 4(4)$ & $108 \pm 4$ & $101 \pm 1(4)$ \\
\hline Anteromedial thalamic nucleus & $117 \pm 6(3)$ & $123 \pm 2$ & $116 \pm 7(4)$ \\
\hline Lateral thalamic nucleus & $112 \pm 7(4)$ & $138 \pm 2(5)^{c}$ & $100 \pm 2(4)$ \\
\hline Ventral thalamic nucleus & $101 \pm 5(4)$ & $116 \pm 3(5)^{a}$ & $92 \pm 4(3)^{d}$ \\
\hline Hypothalamus ventromedial nucleus & $54 \pm 2(4)$ & $51 \pm 2$ & $48 \pm 5(4)$ \\
\hline Medial mamillary nucleus, medial part & $114 \pm 3(4)$ & $135 \pm 4(5)^{c}$ & $104 \pm 3(4)$ \\
\hline Posterior mamillary nucleus & $108 \pm 4(4)$ & $131 \pm 9(5)^{a}$ & $96 \pm 4(4)^{c}$ \\
\hline Lateral geniculate body & $80 \pm 4(4)$ & $78 \pm 3$ & $72 \pm 5(4)$ \\
\hline Medial geniculate body & $116 \pm 2(4)$ & $112 \pm 1$ & $105 \pm 5(4)$ \\
\hline \multicolumn{4}{|l|}{ Mesencephalon } \\
\hline Substantia nigra, pars reticulata & $60 \pm 3(4)$ & $115 \pm 5(5)^{c}$ & $55 \pm 2(4)$ \\
\hline Superior colliculus & $91 \pm 8(4)$ & $88 \pm 2$ & $100 \pm 4(4)$ \\
\hline Interpeduncular nucleus & $103 \pm 3(4)$ & $114 \pm 5$ & $102 \pm 4(4)$ \\
\hline \multicolumn{4}{|l|}{ Medulla/pons } \\
\hline Medial vestibular nucleus & $125 \pm 5(4)$ & $141 \pm 1(5)^{a}$ & $134 \pm 5(4)$ \\
\hline Nucleus of the lateral lemnicus & $92 \pm 6(4)$ & $89 \pm 3$ & $89 \pm 2(4)$ \\
\hline Motor nucleus of the trigeminal nerve & $61 \pm 2(4)$ & $62 \pm 2$ & $61 \pm 6(4)$ \\
\hline \multicolumn{4}{|l|}{ Cerebellum } \\
\hline Cerebellar cortex & $50 \pm 1(3)$ & $71 \pm 2(5)^{c}$ & $58 \pm 4(4)^{e}$ \\
\hline Cerebellar vermis & $59 \pm 4(4)$ & $68 \pm 1$ & $60 \pm 3(4)$ \\
\hline Dentate nucleus & $96 \pm 2(4)$ & $118 \pm 3(5)^{c}$ & $106 \pm 4(4)^{d}$ \\
\hline Interpositus nucleus & $101 \pm 2(4)$ & $123 \pm 3(5)^{b}$ & $107 \pm 6(4)^{e}$ \\
\hline \multicolumn{4}{|l|}{ White matter } \\
\hline Genu of corpus callosum & $31 \pm 2(4)$ & $30 \pm 1$ & $25 \pm 1(4)$ \\
\hline Internal capsule & $31 \pm 2(4)$ & $32 \pm 1$ & $28 \pm 1(4)$ \\
\hline Cerebellar white & $31 \pm 1(4)$ & $33 \pm 1$ & $29 \pm 1(4)$ \\
\hline
\end{tabular}

Values shown are means \pm SEM for the number of rats shown in parentheses.

${ }^{a} p<0.05,{ }^{b} p<0.01,{ }^{c} p<0.001$ significantly different from vehicle.

${ }^{d} p<0.05,{ }^{e} p<0.01,{ }^{f} p<0.001$ significantly different from DMCM $(1 \mathrm{mg} / \mathrm{kg})$.

case of diazepam, this results in a decreased activity in ncurons that are under active GABAergic control and in the case of FG 7142 in an increase. Since neuronal activity is closely related to glucose utilization, this fact may underlie the decreases and increases in glucose utilization induced by diazepam and FG 7142 , respectively. The mediation of the effects of FG 7142 via the benzodiazepine receptor was confirmed by the ability of the specific benzodiazepine antagonist Ro 15-1788 to altenuate the LCGU increases induced by FG 7142 .

Of further interest is that the pattern of regional alteration of LCGU induced by FG 7142 (Cruce, 1979) was strikingly similar to the changes observed in animals undergoing diazepam with- drawal (Ablcitncr ct al., 1985). Thus, administration of the antagonist Ro 15-1788 to rats chronically treated with diazepam resulted in an increase of $\mathrm{LCGU}$ in the same regions as those affected by FG 7142. Moreover, the symptoms accompanying diazepam withdrawal are similar to the effects produced by FG 7142 , that is, anxiety, tremor, and even convulsions (Lukas and Griffiths, 1982; Lader, 1984).

A most pronounced increase in LCGU was seen in the mamillary body, a part of a circuit within the limbic system described by Papez. The mamillary body projects via the mamillothalamic tract to the anterior thalamic nuclei (Cruce, 1979; Holstege and Dekker, 1979), which likewise displayed increased LCGU. Since 


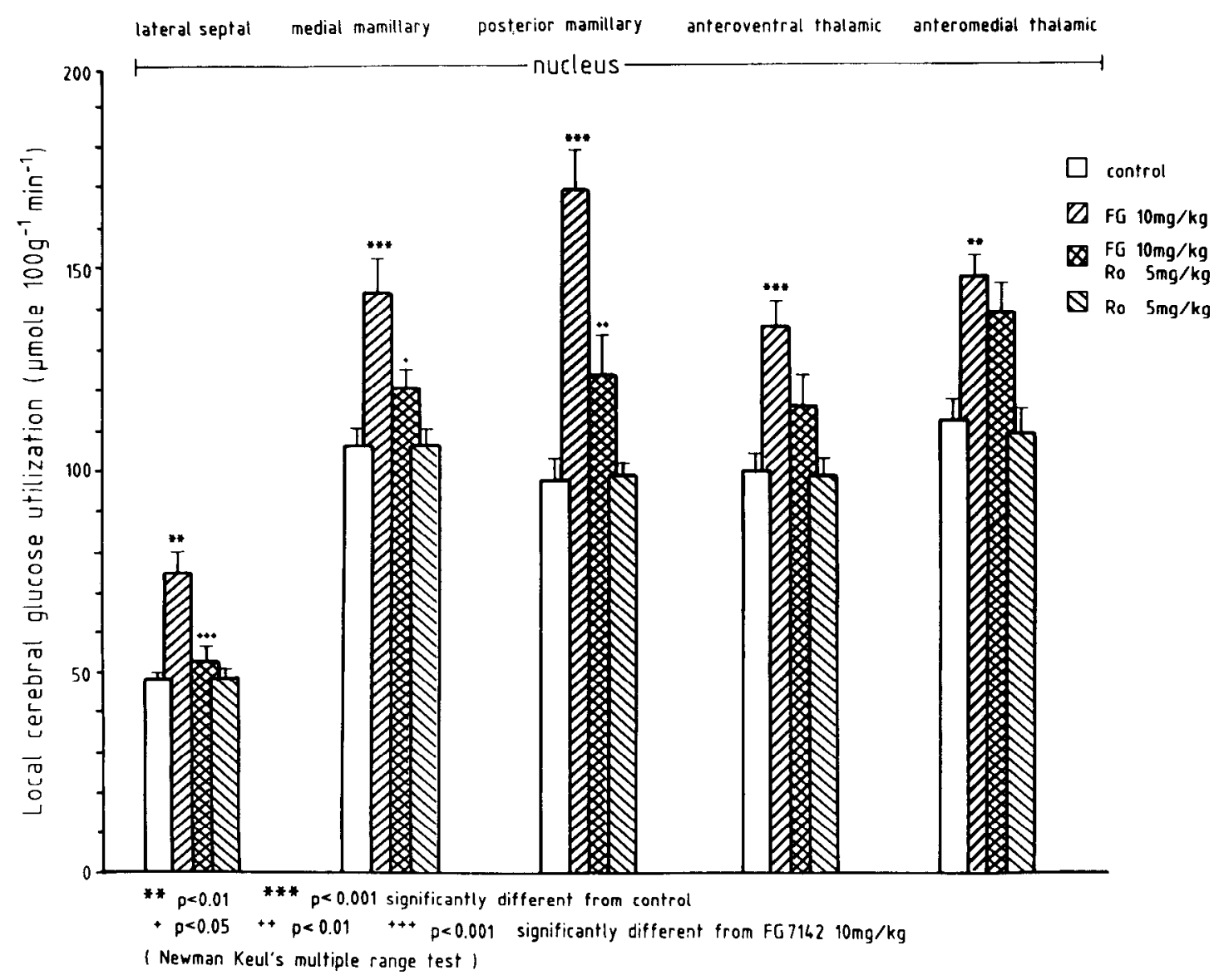

Figure 3. Reversibility of the effects of FG 7142 on LCGU by Ro 15-1788 in limbic structures.

lesions of the mamillothalamic tract prevented this increase in the anterior nuclei of the thalamus (unpublished observations), it may be induced by an increase in the stimulatory input from the mamillary body. This pronounced influence of FG 7142 (and diazepam) upon LCGU in the mamillary body reinforces recent functional studies indicating that this structure plays a critical role in the generation and control of anxiety (Katahoa et al., 1982).

Another circuit within the limbic system, one closely connected with the Papez circuit, is the septohippocampal circuit. FG 7142 induced a strong elevation in LCGU in the lateral septal area, which has generally been implicated in the modulation of anxiety (Gray, 1982).

The substantia nigra, a structure fulfilling a role in the control of motor function, displaycd an increase in LCGU in response to FG 7142, whereas diazepam reduced LCGU in this area (Ableitner et al., 1985). The changes in anatomically associated regions such as the ventral thalamic nucleus, the globus pallidus, and the deep cerebellar nuclei are probably, at least partially, due to an increased input from the substantia nigra. Indeed, in line with this contention, recent studies on the effect of unilateral electrical stimulation of the substantia nigra have demonstrated an increase of LCGU in these regions (Savaki et al., 1983). It is likely that the motor effects (twitches, gnawing) induced by FG 7142 are related to the increased neuronal activity in the substantia nigra and associated areas. Moreover, the occurrence of gnawing may be reflected by the increase of LCGU in the motor nucleus of the trigeminal nerve.
In contrast to FG 7142 , DMCM is a potent convulsant, and it elicited seizures closely resembling those evoked upon kindling of limbic structures (Racine, 1972), such that the pattern of regional alterations in glucose utilization seen should be related to sites involved in ictal onset and spread. However, since the seizures were short compared with the experimental period, the LCGU of these sites might, in addition, be modulated by postictal events occurring within the experimental period. DMCM possesses a high affinity for specific benzodiazepine binding sites (Braestrup et al., 1983a), and the seizures, which appear to be induced by functional disruption of the GABAbenzodiazepine-receptor chloride channel complex were totally prevented by the selective benzodiazepine antagonist Ro 15 1788 (Braestrup et al., 1982). Correspondingly, the effect on LCGU was also prevented by Ro 15-1788.

Predominantly 2 systems were affected by DMCM: the limbic system and, to a greater extent, the extrapyramidal motor system. This pattern of change displayed similarities, but also differences, to the regions affected by diazepam and FG 7142. For example, the LCGU of the hippocampal formation was increased by DMCM, whereas it was unaffected by FG 7142. This could be related to the different binding properties of these drugs. Whereas DMCM has a high binding affinity, the affinity of FG 7142 is more than 100 times lower, and these drugs seem to label different subclasses of receptors in the hippocampus (Braestrup et al., 1983a). Further, DMCM was used at a dosage that elicited a seizure, whereas FG 7142 induced only occasional jerks. The hippocampal formation has an extremely low thresh- 
old for initiation of paroxysmal electrical activity leading to seizure discharges. Since DMCM possesses a high affinity for hippocampal benzodiazepine receptors (Braestrup et al., 1983a, b), one could assume that a primary site of action at the hippocampus is responsible for ictal onset. The change in other limbic structures may therefore reflect the spread of activity through limbic circuits from this site. Thus, afterdischarges initiated within the hippocampal formation by stimulation have been shown to increase glucose utilization in the lateral septum and the nucleus accumbens (Kliot and Poletti, 1979), structures in which we found LCGU increases. The lateral septum, in turn, may have a reciprocal influence on the activity of the hippocampus via the medial septal area (Raisman, 1966; Meibach and Siegel, 1977; Krayniak et al., 1980).

The hippocampus projects to the mamillary body (Swanson, 1978), and this may partially relate to the change in LCGU therein. However, there is also very probably a direct action in this region relating to the anxiogenic effects of DMCM, analogous to the effects of FG 7142 and diazepam.

A very pronounced increase in LCGU was apparent in the substantia nigra, pars reticulata by DMCM. Electrophysiological studies of the firing rate of substantia nigra, pars reticulata cells have, indeed, revealed a dose-related effect of DMCM (Mereu et al., 1983). Further, studies of the seizures evoked by stimulation of limbic structures have also demonstrated a pronounced increase of LCGU in this region (Kaneko et al., 1981; Wasterlain et al., 1981). Thus, in addition to a primary effect upon the substantia nigra, pars reticulata, there may be a secondary effect by spread of limbic activity. The increases in LCGU in the globus pallidus, ventral thalamic nucleus, and cerebellar nuclei are presumably induced via afferent pathways from the substantia nigra.

The present experiments found a contrasting regional distribution of alterations in glucose utilization induced by the $\beta$-carbolines FG 7142 and DMCM. Both drugs exert their effects via the benzodiazepine receptor, as revealed by the antagonism of their effects by Ro 15-1788. The differences in the regional distribution of LCGU changes partially reflect the fact that DMCM is a convulsant, in contrast to FG 7142, a proconvulsant. On the other hand, differences in binding affinities for heterogenous benzodiazepine receptors within the various regions of the limbic system might also be responsible.

\section{References}

Ableitner, A., M. Wüster, and A. Herz (1985) Specific changes in local cerebral glucose utilization in the rat brain induced by acute and chronic diazepam. Brain Res. 359: 49-56.

Asano, T., and S. Spector (1979) Identification of inosine and hypoxanthine as endogenous ligands for the brain benzodiazepine binding sites. Proc. Natl. Acad. Sci. USA 76: 977-981.

Braestrup, C., M. Nielsen, and C. E. Olsen (1980) Urinary and brain $\beta$-carboline-3-carboxylates as potent inhibitors of brain benzodiazepine receptors. Proc. Natl. Acad. Sci. USA 77: 2288-2292.

Braestrup, C., M. Nielsen, H. Scovbjerg, and O. Gredal (1981) $\beta$-Carboline-3-carboxylates and benzodiazepine receptors. In $G A B A$ and Benzodiazepine Receptors, E. Costa et al., eds., pp. 147-155, Raven, New York.

Braestrup, C., R. Schmiechen, G. Neef, M. Nielsen, and E. N. Petersen (1982) Interaction of convulsive ligands with benzodiazepine receptors. Science 216: 1241-1243.

Braestrup, C., M. Nielsen, and T. Honore (1983a) Binding of [ $\left.{ }^{3} \mathrm{H}\right] \mathrm{DMCM}$, a convulsive benzodiazepine ligand, to rat brain membranes: Preliminary studies. J. Neurochem. 41: 454-465.

Braestrup, C., M. Nielsen, T. Honore, L. H. Jensen, and E. N. Petersen (1983b) Benzudiazepine receptor ligands with positive and negative efficacy. Neuropharmacology 22: 1451-1457.

Corda, M. G., W. D. Blaker, W. B. Mendelson, A. Guidotti, and E. Costa (1983) $\beta$-Carbolines enhance shock-induced suppression of drinking rats. Proc. Natl. Acad. Sci. USA 80: 2072-2076.

Cruce, J. A. F. (1979) An autoradiographic study of the projections of the mamillothalamic tract in the rat. Brain Res. 85: 211-219.

Dorow, R., R. Horowski, G. Paschelke, M. Amin, and C. Braestrup (1983) Severe anxiety induced by FG 7142, a beta carboline ligand for benzodiazepine receptors. Lancet 2: 98-99.

Dow-Edwards, D. L., M. Down, J. M. Peterson, S. S. Rapport, and E. D. London (1981) Effects of oxotremorine on local cerebral glucose utilization in motor system regions of the rat brain. Brain Res. 226 . 281-289.

File, S. E., and S. Pellow (1984) FG 7142, a $\beta$-carboline, has an anxiogenic action in the social interaction test. Br. J. Pharmacol. 82: 240.

Gray, J. A. (1982) The Neuropsychology of Anxiety, Clarendon Press, Oxford (Oxford U. P., New York).

Guidotti, A., G. Toffano, and E. Costa (1978) An endogenous protein modulates the affinity of GABA and benzodiazepine receptors in rat brain. Nature 275: 553-555.

Guidotti, A., C. M. Forchetti, M. G. Corda, D. Konkel, C. D. Bennet, and E. Costa (1983) Isolation and characterization and purification to homogeneity of an endogenous polypeptide with agonistic action on benzodiazepine receptors. Proc. Natl. Acad. Sci. USA 80: 3531.

Holstege, J. C., and J. J. Dekker (1979) Electron microscopic identification of mamillary body terminals in the rat AV thalamic nucleus by means of anterograde transport of HRP. A quantitative comparison with the EM degeneration and FM autoradiographic techniques. Neurosci. Lett. 11: 129-135.

Kaneko, Y., J. A. Wada, and H. Kimura (1981) Is the amygdaloid neuron necessary for amygdaloid kindling. In Kindling 2, J. A. Wada, ed., pp. 249-264, Raven, New York.

Katahoa, Y., S. Kazuhico, Y. Gomita, and S. Ueki (1982) The mamillary body is a potential site of antianxiety action of benzodiazepines. Brain Res. 241: 374-377.

Kliot, M., and C. E. Poletti (1979) Hippocampal afterdischarges: Differential spread of activity shown by the ${ }^{14} \mathrm{C}$-deoxyglucose technique. Science 204: 641-643.

König, J., and R. Klippel (1963) The Rat Brain: A Stereotaxic Atlas of the Forebrain and Lower Parts of the Brain, Waverly, Baltimore, MD.

Krayniak, P. F., S. Weiner, and A. Siegel (1980) An analysis of the efferent connections of the septal area in the cat. Brain Res. 189: 1529.

Lader, M. (1984) Benzodiazepine dependence. Prog. Neuro-Psychopharmacol. Biol. Psychiatry 8: 85-95.

Little, J. H., D. J. Nutt, and S. C. Taylor (1984) Acute and chronic effects of the benzodiazepine receptor ligand FG 7142: Proconvulsant properties and kindling. Br. J. Pharmacol. 83: 951-958.

Lukas, S. E., and R. R. Griffiths (1982) Precipitated withdrawal by a benzodiazepine receptor antagonist (Ro 15-1788) after 7 days of diazepam. Science 217: 1161-1163.

Meibach, R. C., and A. Siegel (1977) Efferent connections of the septal area in the rat: An analysis utilizing retrograde and anterograde transport methods. Brain Res. 119: 1-20.

Mereu, G., B. Fanni, M. Serra, A. Concas, and G. Biggio (1983) $\beta$-Carbolines activate neurons in the substantia nigra pars reticulata: An effect reversed by diazepam and Ro 15-1788. Eur. J. Pharmacol. 96: 129-132.

Möhler, H., and T. Okada (1977) Benzodiazepine receptor: Demonstration in the central nervous system. Science 198: 849-851.

Möhler, H., P. Polc, R. Cumin, L. Pieri, and R. Kettler (1979) Nicotinamide is a brain constituent with benzodiazepine-like actions. Nature 278: 563-565.

Nutt, D. J., P. J. Cowen, and H. J. Little (1982) Unusual interaction of benzodiazepine receptor antagonists. Nature 295: 436.

Palacios, J. M., M. J. Kuhar, S. J. Rapport, and E. D. London (1982) Effect of $\gamma$-aminobutyric acid agonist and antagonist drugs on local cerebral glucose utilization. J. Neurosci. 2: 853-860.

Pellegrino, L. J., A. S. Pellegrino, and A. J. Cushman (1981) A Stereotaxic Atlas of the Rat Brain, Plenum, New York.

Petersen, N. E. (1983) DMCM: A potent convulsive benzodiazepine receptor ligand. Eur. J. Pharmacol. 94: 117-124.

Racine, R. J. (1972) Modification of seizure activity by electrical stimulation: II. Motor seizure. Electroencephalogr. Clin. Neurophysiol. 32: $281-294$. 
Raisman, G. (1966) The connections of the septum. Brain 89: 317348.

Savaki, H. E., L. Davidsen, C. Smith, and L. Sokoloff (1980) Measurement of free glucose turnover in brain. J. Neurochem. 35: 495502.

Savaki, H. E., M. Derban, J. Glowinski, and M.-J. Besson (1983) Local cerebral glucose consumption in the rat. II. Effects of unilateral substantia nigra stimulation in conscious and in halothane-anesthetized animals. J. Comp. Neurol. 213: 46-65.

Sokoloff, L., M. Reivich, D. Kennedy, M. H. DesRosier, C. S. Patlak, K. D. Pettigrew, O. Sakurada, and M. Shinohara (1977) The ${ }^{14} \mathrm{C}-$ deoxyglucose method for the measurement of local cerebral glucose utilization: Theory, procedure, and normal values in the conscious and anesthetized albino rat. J. Neurochem. 28: 897-916.

Squires, R. F., and C. Braestrup (1977) Benzodiazepine receptors in rat brain. Nature 266: 732-734.

Wasterlain, C. G., D. Masouka, and V. Jonec (1981) Chemical kindling: A study of synaptic pharmacology. In Kindling 2, J. A. Wada, ed., pp. 315-329, Raven, New York.

Young, W. S., III, and M. J. Kuhar (1980) Radiohistochemical localization of benzodiazepine receptor in rat brain. J. Pharmacol. Exp. Ther. 212: 337-346. 